\author{
Richard P. Smiraglia \\ Long Island University, Brookville New York, USA
}

\title{
Performance works: Continuing to comprehend instantiation
}

\begin{abstract}
Much work in knowledge organization (KO) is conceptual, which results in a theoretical framework that is itself largely conceptual. In some cases empirical methods have been employed as well for direct observation of phenomena. Direct observation provides a critical base point and a variety of empirical approaches have been used to good effect in KO. The phenomenon of instantiation has been examined to date almost entirely based on the analysis of data derived from empirical analysis. In the present paper we demonstrate the efficacy of the empirical model for category generation by taking one category of instantiation - the performance work - and submitting it to analytical scrutiny. Data from three analytical studies are reviewed and placed alongside evidence from datasets gathered for prior studies on instantiation. A performance work is realized in space and time, and thus exists spatiotemporally. The performance work might be derived from a precedent work, related to other works that are embedded, have adjunct documentation, and be accompanied by antecedent works. A naïve classification is derived empirically, a model follows rationally, and together with semiotic elements a partial typology is generated that represents the essential knowledge elements from which a KO schema for performance works might evolve.
\end{abstract}

\section{Empirical analysis for category generation}

Much work in knowledge organization (KO) is conceptual, which results in a theoretical framework that is itself largely conceptual. In some cases empirical methods have been employed as well, primarily for testing components of retrieval systems. Hjørland (2003) has suggested that attention focused on four fundamental epistemic stances could improve the theoretical position of research in KO. These four stances are (2003, 107): empiricism (observations and inductions), rationalism (principles of pure reason, deductions), historicism (study of context and development; explicating pre-understanding), and pragmatism (analysis of goals, values and consequences in both subject and object). All four points of view are important, but in the development of new systems for KO direct observation of phenomena provides a critical base point, from which rationalism may subsequently provide conceptual connections and greater sophistication. Beghtol (2003) has described this process as the development of naïve classification systems, which are generated as a part of scholarship and which allow scholars to ask new questions of newly revealed data.

Also, Hjørland (2004) has described the use of concepts in $\mathrm{KO}$ as political, suggesting that no KO can ever be neutral or completely bias free. He then appealed to information policy to arrive at a proposed alternative to neutrality and freedom from bias (p. 9): "KO should be based upon an analysis of conflicting views and interests as well as upon explicit arguments on which basis the concepts should be defined and organized." He concludes that different 
Smiraglia, R. P. (2007). Performance works: Continuing to comprehend instantiation. Proceedings of North American Symposium on Knowledge Organization. Vol. 1. Available:

http://dlist.sir.arizona.edu/1910

conceptualizations from differing discourse communities should be made visible and navigable in KO systems. This, too, suggests that the use of empirical bases for the generation of $\mathrm{KO}$ systems is important in order to make visible alternative viewpoints.

In fact, a variety of empirical approaches have been used to good effect. Beghtol (1995) used quantitative techniques to create a composite statistical picture of the subject field of periodical literature about fiction. Saarti (2000) and Albrechtsen and Pejtersen (2003) are examples of qualitative approaches. Saarti employed content analysis of abstracts generated by users and librarians in Finnish public libraries to generate a taxonomy of novel abstracts. Albrechtsen and Pejtersen used cognitive work analysis to capture evolving semantic structures in specific work domains. Greenberg (2005) and Howarth (for example, 2000 and 2003) have demonstrated the efficacy of empirical methods for generation of metadata structures for resource description and discovery. Smiraglia (2002) summarized advances in content and formation of library catalogs that can be attributed to empirical methods. Hjørland has also appealed to activity theory (2003) to help in comprehending the value of empirical research for resource description.

Dahlberg (2007) distinguishes among knowledge-elements, which are the basic entities in $\mathrm{KO}$, and knowledge-units and knowledge-systems, which are the rational conceptual entities that provide structure for $\mathrm{KO}$. The empirical derivation of knowledge-elements, particularly in developing or evolving KO systems, provides a basis upon which conceptual systems can be built. This is exactly the approach called naïve classification by Beghtol (2003), who suggests such schemes are particularly appropriate for use in evolving scholarship.

Growth of understanding of the phenomenon of instantiation (Smiraglia, 2005) has all been based on the analysis of data derived from empirical analysis of random samples of works, museum artifacts, and archival documents. Evidence gathered through these analyses is presented as a typology of instantiation (Smiraglia, 2006), an emergent naïve classification of the knowledge-elements that constitute the phenomenon of multiple realization of informing content over time. In the present paper I further demonstrate the efficacy of the empirical model for category generation by taking one category of instantiation-the performance work-and submitting it to analytical scrutiny.

\section{What exactly constitutes performance?}

For the purpose of analysis we will compare data from several studies. Miller and LeBoeuf (2005) generated typology of the documents associated with the performing arts. Procházka (2006) analyzes documents associated with choreographic notation. Doerr and Bekiari (2006) construct an object oriented map of the elements of performance using what they term a "value-added-chain." These three analyses are reviewed and then placed alongside evidence from datasets gathered for prior studies on instantiation. Let us begin by considering the definition of the term "performance." 
Smiraglia, R. P. (2007). Performance works: Continuing to comprehend instantiation. Proceedings of North American Symposium on Knowledge Organization. Vol. 1. Available:

http://dlist.sir.arizona.edu/1910

\subsection{Epistemological analysis of performance}

The Oxford English Dictionary Online was consulted for the definition of "performance." The following facts emerge:

-carrying out of something; doing of an action

-quality of execution of an action

-something done

-observable or measurable behavior

-execution of a play or musical work

•the instance of an execution ...

-made up of Per (in space and/or in time to completion), and Form (to give shape to, to express) to make Perform (to carry out), and Ance (instance)

Performance, then, is always active - an action taken in space and in time. There are two senses of performance: 1) the action itself-we will call this performance proper; and 2) an instance of the action (as in its representation or its reception), which we will call a performance event.

\subsection{Performing arts, performances, performance works}

What, then, is a "performance work?" The simple answer is that a performance work is a work created for the purpose of generating a performance. Miller and LeBeouf (2005) identify components of a performance work. A live performance is a "spatiotemporal event" (p. 167), whose chronology is the duration of the performance event. However, in the performing arts it is common for performances to be repeated in series called "runs" (a run might have only a single performance event associated with it). On occasion performance runs are "revived." Miller and Leboeuf suggest that a run is parallel to a publication, and the sum of the durations of all runs and revivals of a given performance are parallel to an edition (p. 168). The content of a performance is a semiotic system (p. 168): "a set of spatiotemporal signs-uttered words, sounds, light, colors and other visual effects, symbols, movements, rhythm, psychological use of sheer time-lapse, etc."

Miller and LeBoeuf are concerned with the sets of documents that might be generated in support of live performances and that might, thus, be collected by libraries. Following a very thorough review of the treatment of performance works in Anglo-American cataloging tradition they develop a typology of expressions (choreography, mise-en -scène), and of manifestations e.g., kinetic notation of choreography), as well as related materials including design models, costumes, photographs, clippings, program booklets, etc. The FRBR model (IFLA, 1998) is then used to map elements of live performance. The FRBR model stipulates a chain from the abstract work, which is expressed when realized, manifested in concrete form that finds physical reality in an item. Their map appears as Figure 1 below (Miller and LeBoeuf, 2005, 172). 


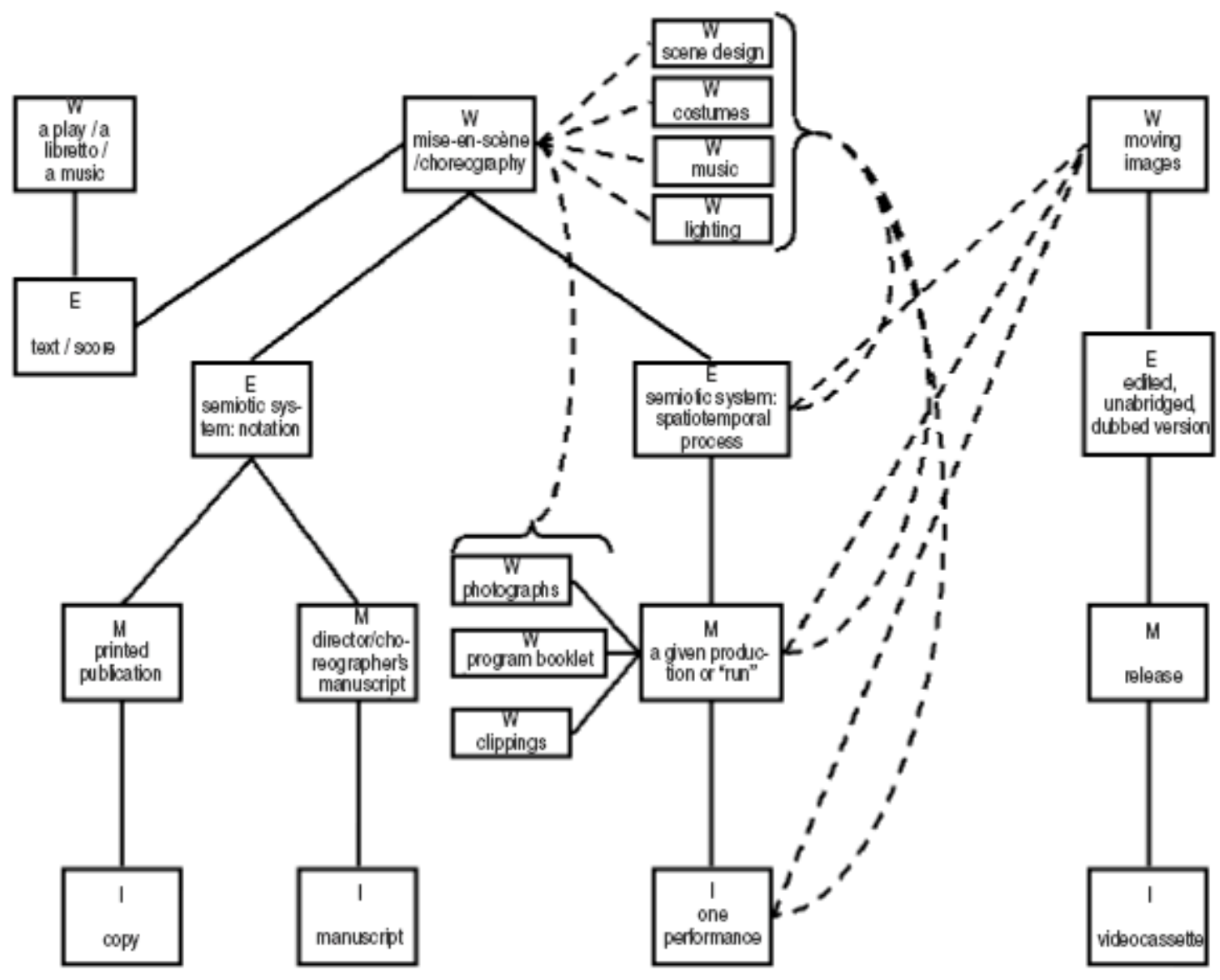

Figure 1. Miller-LeBoeuf FRBR mapping

Procházka (2006) documents the development of cataloging techniques for representations of choreographic works. To explain the complexity of access points required by various cataloging codes, several examples of choreographic "works" are given. These are helpful for understanding the nature of performance works. For example (p. 8-9):

-A collection of photographs documenting Mark Morris' The Hard Nut, which uses Tchaikovsky's music for The Nutcracker

- Choreographic works that combined numerous works by a single composer ... the ballet Les Sylphides also known as Chopiniana, Chopinade, ... comprised of different short piano pieces by Frederic Chopin arranged for orchestra, and was first choreographed by Michel Fokine in 1907.

The solution makes use of uniform title structure, and uses as its model the precedent set for serial publications that require qualification or motion pictures. Here the precedent involves 
Smiraglia, R. P. (2007). Performance works: Continuing to comprehend instantiation. Proceedings of North American Symposium on Knowledge Organization. Vol. 1. Available:

http://dlist.sir.arizona.edu/1910

representation of works with complex attribution under the titles by which they are known. A choreographic work might then be represented thus (p. 11):

Hard nut (Choreographic work : Morris) ...

Sylphides (Choreographic work : Fokine) ...

Paquita (Choreographic work : Makarova after Petipa, M.)

The choreographic work - a kind of performance work-has kinetic instructions that constitute a kind of score of the work. The performance itself then is the action on the stage and the work is realized in real time in the performance event. The performance work has adjunct documents that might include a score, a visual recording, one or more photographs, etc. And there are related works as well, that are utilized in the performance work-the musical works, the costumes, etc.

\subsection{Performance as added-value-chain}

The CIDOC-Conceptual Reference Model (CIDOC-CRM) is a common language for information sharing among museums, libraries, and archives. Since 2006 the CRM has had the status of an official standard ISO 21127:2006. The CRM is an empirically derived language that supplies "definitions and formal structure for describing the implicit and explicit concepts and relationships used in cultural heritage documentation" (http://cidoc.ics.forth.gr/). A powerful template for knowledge sharing, the CRM has been conformed to several knowledge models for cultural resources including FRBR, which has been reengineered by the FRBR/CRM working group into an object-oriented model known as FRBRoo (http://cidoc.ics.forth.gr/frbr_drafts.html). The phenomenon of instantiation has been extended into the basic language of the CRM, incorporating not only the research reported here but also semiotic theory. Major physical entities are Creation, Production, Conceptual Object, and Information Carrier, which are the "things" of information resources. Work and Expression are major intellectual entities, which are acknowledged to act as signs. The substance of a work, always, is ideational content - ideas.

Doerr and Bekiari (2006) extended the FRBRoo model to performances via the production of what they call an added-value-chain. Their model is too complex to reproduce here but we can paraphrase its key elements. A performance is considered a "complex work," which might be realized as an individual work and expressed as a given play (for example). This set then becomes a performance work through a chain of "added value," as for example when it is adapted for stage via a performance plan (a mise-en-scène), which is then performed by actors in the presence of public. The value-chain proceeds from writers, through directors and performers, all instantiations of which are mediated by physical documents.

\section{Bibliographical evidence about performance instantiation networks}

Over the past two decades data files from prior studies of works and instantiation networks have been compiled through the use of simple random sampling. The five datasets 
came from the Georgetown University Libraries, OCLC WorldCat, theological collections at New York University's Bobst Library and the library of the Union Theological Seminary, Bestsellers of the $20^{\text {th }}$ century, and American literature drawn from Books In Print- (see Smiraglia, 2001, 2007 and Marchese, 2002). Each dataset was consulted to find all works that displayed performance relations. In the five studies there were 61 such works.

Analysis of the data reveals the phenomenon as pervasive, but with no apparent pattern as it concerns what sort of works might become performances. As might be expected, fiction is well represented as are drama and music, biography and criticism. The majority of the performances in these studies are motion pictures, although there are also sound recordings and television plays. We must acknowledge at once that we are dealing with recordings of performances, one more link on the Doerr-Bekiari added-value-chain. The majority (all but two of 61) are from the $20^{\text {th }}$ century. All but three were in English originally. No statistical significance is to be attached to these findings; rather we can consider them interesting pointers. When the most complex instantiation networks were compared to the most complex performance networks, a set of twelve works emerged from which 6 fell into both categories. These were:

-Henry, O. 1906. Gift of the magi. Fiction. 76 performances.

-Wharton, Edith. 1911. Ethan Frome. Fiction. 33 performances.

-Puzo, Mario. 1969. The Godfather. 60 performances. Fiction.

-Steinbeck, John. The grapes of wrath. 47 performances. Fiction.

-Wister, Owen.1902. The Virginian. 23 performances. Fiction.

-Shaw, George Bernard. 1924. Saint Joan. 23 performances.

Instantiation networks of the recorded performances were compiled from OCLC for each of these six works. Broad categories emerged, which are shown in Table 1.

\begin{tabular}{|l|}
\hline Books on tape, Audio books, etc. \\
\hline Sign-language CD-ROM \\
\hline Filmstrips with sound and script for teacher \\
\hline Videorecording in American sign language \\
\hline Kit with spirit masters, transparencies, etc. \\
\hline Screenplay \\
\hline Motion picture \\
\hline Videorecording of motion picture \\
\hline Videorecording of television production \\
\hline Musical recordings of musical derivative work \\
\hline
\end{tabular}

Table 1. Recorded performances as instantiation networks

Bibliographic instantiation networks were not revisited at this time, although earlier analyses have demonstrated the catalytical role of the public acceptance of a performed work. That is, a literary work, for instance, that becomes the basis of a motion picture, will then spawn a large, complex instantiation network of novelizations of the screenplay, lunch boxes, action figures, generations of video and audio recordings, etc., etc. 
Above we acknowledged that recordings of performances require us to consider one more layer of intention beyond the performance itself. Thus recordings are usually considered antecedent to the performance work, although not necessarily to the performance event. Consider for example, a motion picture, which consists of edited recorded performances linked subsequently to form the performance work. In this case, the recording is not antecedent but rather is a part of the technology of producing the performance work. We might also consider the recording of a live performance of an opera or concert, which is made in real time, simultaneous with the performance event. Here, too, the recording is not necessarily antecedent to the performance event. But, if we consider the case of a performance recording released for sale to the public together with out-takes, interviews, extra music, and perhaps a booklet, then we have a clearly antecedent production. In fact, the latter case (the public release) is a manifestation of the recording, whereas the earlier instances represent expressions that we might consider "recording works." An essential difference then between expression and manifestation is chronology.

Thus the common components of a "recording work" are:

-the recording captures a performance event;

-the activity of recording is deliberate, creative, accomplished through technology;

-the product is itself a recording work;

-the "recording work" has the characteristics of a work, including the distinction between expression and manifestation, and the potential for instantiation.

Therefore it is important to make a distinction between the characteristics of the recording work and those of the captured work.

\section{Empirical category generation and performance works}

Let us begin by compiling the knowledge-elements (Dahlberg's first level) from the studies we have analyzed here. Table 2 includes terminology representing these entities, and thus constitutes a naïve classification of performance works.

\begin{tabular}{|c|c|c|}
\hline Miller-LeBoeuf & Procházka & Smiraglia \\
\hline $\begin{array}{l}\text { Expressions: choreography, } \\
\text { mise-en -scène. } \\
\text { Manifestations: kinetic } \\
\text { notation of choreography. } \\
\text { Related Materials: design } \\
\text { models, costumes, } \\
\text { photographs, clippings, } \\
\text { program booklets }\end{array}$ & $\begin{array}{l}\text { Adjunct Documents: a score, } \\
\text { dance notation, a visual } \\
\text { recording, one or more } \\
\text { photographs, etc. }\end{array}$ & $\begin{array}{l}\text { Recorded Performances: } \\
\text { Books on tape, Audio books, } \\
\text { etc., Sign-language CD-ROM } \\
\text { Filmstrips with sound and } \\
\text { script for teacher, } \\
\text { Videorecording in American } \\
\text { sign language, Kit with spirit } \\
\text { masters, transparencies, etc., } \\
\text { Screenplay, Motion picture, } \\
\text { Videorecording of motion } \\
\text { picture, Videorecording of } \\
\text { television production, Musica } \\
\text { recordings of musical }\end{array}$ \\
\hline
\end{tabular}




\begin{tabular}{|l|l|l|}
\hline $\begin{array}{l}\text { Spatiotemporal Events: run, } \\
\text { revival }\end{array}$ & $\begin{array}{l}\text { Choreographic Works: } \\
\text { photographs, of dance, set to } \\
\text { music }\end{array}$ & derivative work \\
\hline $\begin{array}{l}\text { Spatiotemporal Signs: uttered } \\
\text { words, sounds, light, colors } \\
\text { and other visual effects, } \\
\text { symbols, movements, rhythm, } \\
\text { psychological use of sheer } \\
\text { time-lapse }\end{array}$ & $\begin{array}{l}\text { Related Works: the musical } \\
\text { works, the costumes, etc. }\end{array}$ & \\
\hline
\end{tabular}

Table 2. Empirically generated knowledge elements

According to Beghtol $(2003,69)$, this most closely parallels the paradigm method, which involves a matrix of axes and attributes. In the columns of the table are terms generated empirically in the studies examined here that describe the entities associated with performance works. But running across the table from left to right in the lower rows is the concept of the spatiotemporality of performance, and of the semiosis of performance.

Assembling these elements into knowledge-units (Dahlberg's second level) requires the application of rationalism to provide conceptual links. In so doing we can move forward from the naïve classification toward a more sophisticated model that embraces the semiotic elements of performance. We can see that a performance work is realized in space and time; as it were, "in performance," and thus will exist spatiotemporally as a "run" (even if as a run of only one performance event). A run might "revived," at some chronological distance from an initial performance event. The performance work might be derived from a precedent work (e.g., a literary work). It likely is related to other works that are embedded in the performance (musical works, costumes, sets, and their representations, such as models, diagrams, or photographs), and that have adjunct documentation (instructions for performance, scores, programs). There often are antecedent works (photographs, clippings, recordings). A graphical representation might look something like Figure 2. 


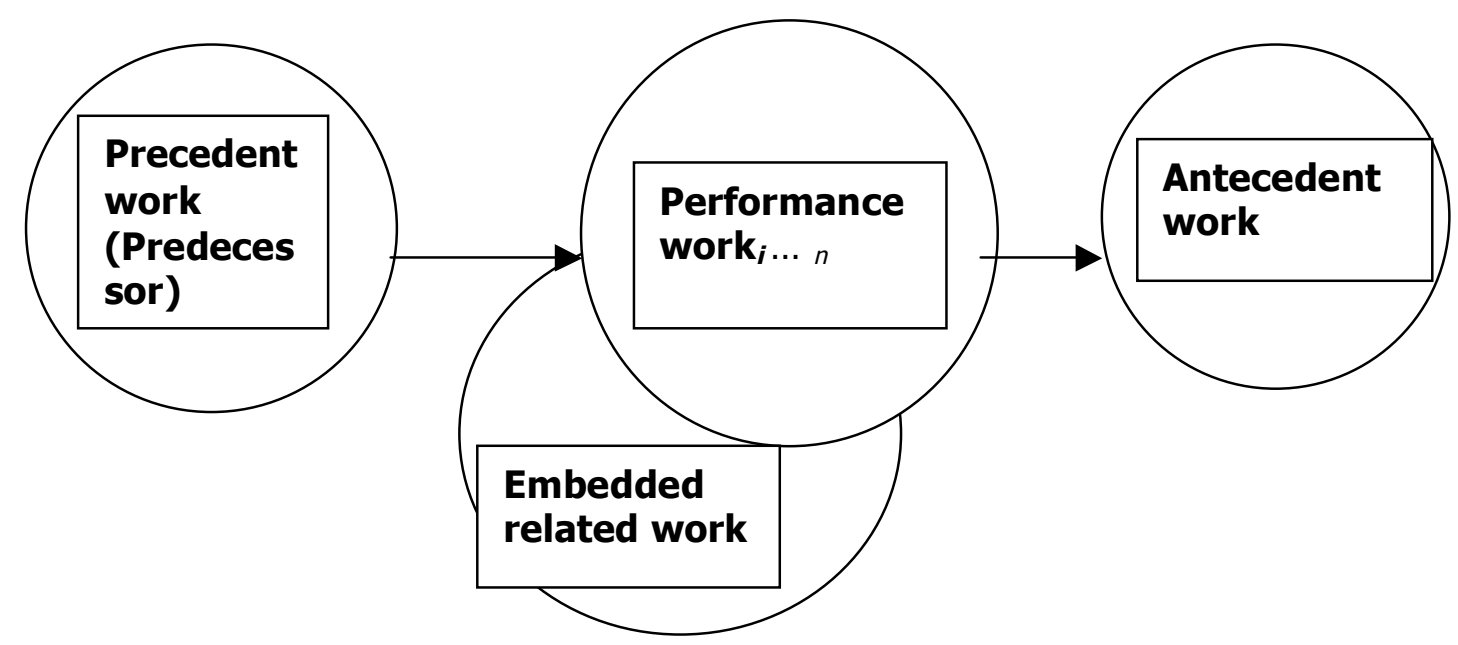

Figure 2. Modeling a performance work

A partial typology can now be generated (Table 3). This represents the essential knowledgeunits from which a KO schema for performance works might evolve.

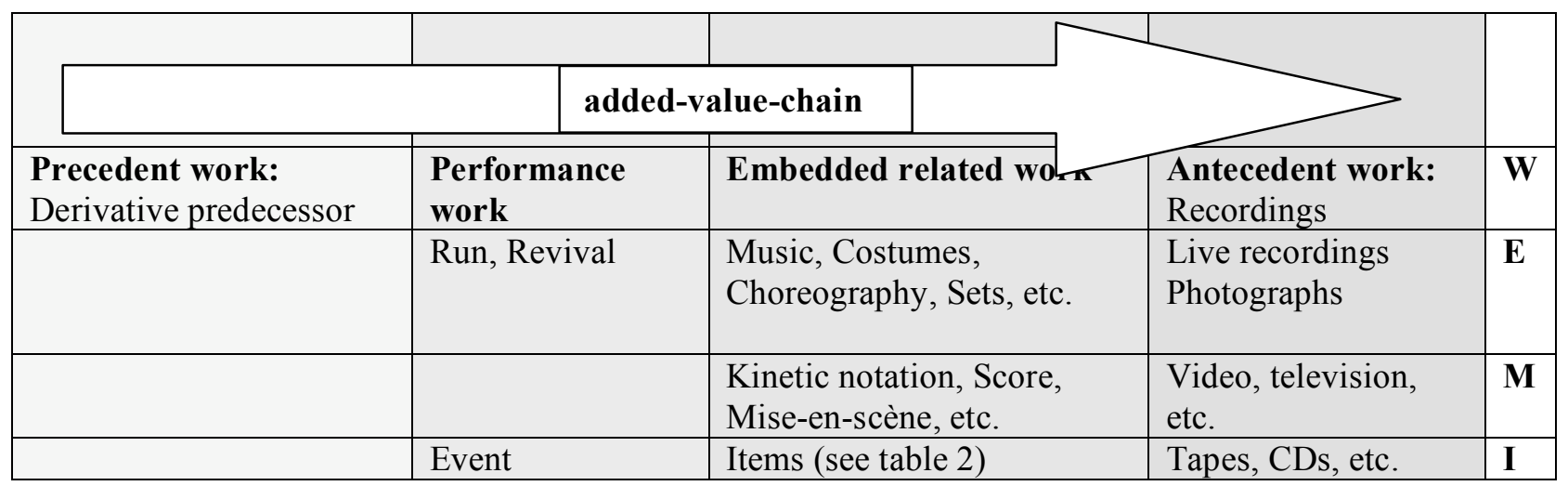

Table 3. Partial typology of performance components

Semiotic motion flows both left to right and top to bottom. Value is added in the chronological span of a performance work as works (ideational abstractions) by different creators are added together across the chain. The FRBR mapping in the right column shows semiotic motion as ideas move from abstract work status to instantiation as manifestations. The terms in Table 2 above might be added to the bottom of this table to generate the FRBR item level.

\section{Analysis and discussion}

The purpose of this paper was to demonstrate the use of empirical means to generate a $\mathrm{KO}$ structure, and in particular to highlight the evolution from a naïve classification of simple 
Smiraglia, R. P. (2007). Performance works: Continuing to comprehend instantiation. Proceedings of North American Symposium on Knowledge Organization. Vol. 1. Available:

http://dlist.sir.arizona.edu/1910

knowledge-elements to a more useful model of a phenomenon, incorporating conceptual knowledge-units. In this one case we have generated a sequence that begins with empiricism and incorporates rationalism. We have brought together somewhat divergent aspects of the phenomenon of performance, using data from librarianship, from archival practice, and from information science, and from knowledge representation.

The research we have used in this exercise has all been described as empirical, although it is clear that it all derives from diverse methodological approaches. What is critical in this case is the deliberate, direct observation of the phenomenon under study. As Hjørland reminds us (2003, 107) the various epistemological positions cannot exist in pure forms - any empirical test must be tempered by logical (i.e., rational or pragmatic) thought and is subject to historical interpretation. Therefore methodological pluralism - the incorporation of a broad palette of methods both quantitative and qualitative-has proven effective for the development of a paradigmatic naïve classification and is recommended.

Finally, this exercise has served the purpose of illuminating one type of instantiation. In this we have the potential to move the exercise toward a pragmatic application. Instantiation is the phenomenon observed among informing objects (documents, artifacts, etc.) in which multiple realizations over time are instantiated in diverse sets of physical forms. For information retrieval it is considered desirable both to bring all instantiations together - to cause collocation, essentially an act of classification - as well as to disambiguate the clustered instantiations so as to facilitate retrieval. That is, we want at once to look up all things related to Hamlet under Shakespeare's Hamlet, and at the same time to make a wise choice from among plays, mise-enscènes, videorecordings of performances, motion pictures, and the multiplicity of other artifacts and documents that might have been generated in association with something called Hamlet. In this, instantiation plays the role of metonymy-allowing a classification under a culturally recognized historical anchor (a name). At the same time, fully exploited models of the typology of instantiation can facilitate designs for display and retrieval that make clustering and disambiguation more efficacious.

In this case we have begun to explode one category of instantiation-performance works - which as an abstraction constitutes works that incorporate other works (see Figure 1). From our naïve classification, which has resulted in the model above, we can state that any performance work will have one or all of the attendant components in the model (precedents, antecedents, and embedded works) and that the value-added-chain is one way of comprehending the complexity of performance works. On the other hand, the elements in table 2 do not comprise an exhaustive list, we have not looked at the components in table 3 in detail, nor have we considered the considerable differences between performance of theatrical works, musical works, musical theatre, and so on. But given this basic, naive model and our typology we now may proceed to more critical empirical analysis of the phenomenon of performance works and the artifacts associated with them.

\section{References}

Albrechtsen, H. and Pejtersen, A. M. (2003). Cognitive work analysis and work centered design of classification schemes. Knowledge organization 30: 213-27. 
Smiraglia, R. P. (2007). Performance works: Continuing to comprehend instantiation. Proceedings of North American Symposium on Knowledge Organization. Vol. 1. Available:

http://dlist.sir.arizona.edu/1910

Beghtol, Clare. (1995). Domain analysis, literary warrant, and consensus: the case of fiction studies. Journal of the American Society for Information Science 46: 30-44.

Beghtol, C. (2003). Classification for information retrieval and classification for knowledge discovery: Relationships between "professional" and "naïve" classifications. Knowledge organization 30: 64-73.

Dahlberg, I. (2006). Knowledge organization: a new science? Knowledge organization 33: 1119.

Doerr, M. and Bekiari, C. (2006). Performing arts added-value-chain. PowerPoint slide for CCIICS-FORTH $8^{\text {th }}$ Meeting on FRBR/CRM Harmonization Heraklion, Crete, Greece. Available: http://cidoc.ics.forth.gr/frbr_papers.html (accessed 18 May 2007).

Greenberg, J. (2005). Understanding metadata and metadata schemes. Cataloging \& classification quarterly 40(3/4): 17-36.

Hjørland, B. (2003). Fundamentals of knowledge organization. Knowledge organization 30: 87111.

Hjørland, B. (2004). Theory of knowledge organization and the feasibility of universal solutions. PowerPoint slides for the Eighth International ISKO Conference London Friday July 16, 2004. Available: http://dlist.sir.arizona.edu/389/ (accessed 17 May 2007).

Howarth, L.C. (2000). Designing a 'human understandable' metalevel ontology for enhancing resource discovery in knowledge bases. In Beghtol, C., Howarth, L.C. and Williamson, N.J. eds., Dynamism and stability in knowledge organization; Proceedings of the Sixth International ISKO Conference 10-13 July 2000 Toronto, Canada.Würzburg: Ergon, pp. 391-98.

Howarth, L.C. (2003). Designing a common namespace for searching metadata-enabled knowledge repositories: an international perspective. Cataloging \& classification quarterly 37(1/2): 173-85.

Marchese, C. (2002). Works of American literature. Unpublished term paper, Long Island University.

Miller, D. and LeBoeuf, P. (2005). 'Such stuff as dreams are made on': how does FRBR fit performing arts? Cataloging \& classification quarterly 39(3/4): 151-78.

Procházka, D. (2006). The development of uniform titles for choreographic works. Cataloging \& classification quarterly 42: 7-20.

Saarti, J. (2000). Taxonomy of novel abstracts based on empirical findings. Knowledge organization 27: 213-20.

Smiraglia, R.P. (2001). The nature of a work: implications for the organization of knowledge. Lanham, MD: Scarecrow.

Smiraglia, R.P. (2002). Further progress in theory in knowledge organization. Canadian journal of information and library science 26(2/3): 30-49.

Smiraglia, R.P. (2005). Instantiation: Toward a theory. In Vaughan, L., ed., Data, information, and knowledge in a networked world; Annual conference of the Canadian Association for Information Science ... London, Ontario, June 2-4 2005. Available http://www.caisacsi.ca/2005proceedings.htm.

Smiraglia, R.P. (2006). Empiricism as the basis for metadata categorization: expanding the case for instantiation with archival documents. In Budin, G., Swertz, C. and Mitgutsch, K., 
Smiraglia, R. P. (2007). Performance works: Continuing to comprehend instantiation. Proceedings of North American Symposium on Knowledge Organization. Vol. 1. Available:

http://dlist.sir.arizona.edu/1910

eds., Knowledge organization and the global learning society; Proceedings of the 9th ISKO International Conference, Vienna, July 4-7 2006, pp. 383-88.

Smiraglia, R.P. (2007). The 'works' phenomenon and best selling books. Cataloging \& classification quarterly 44(3/4). 